\title{
THE INTERNATIONAL CONGRESS OF MATHEMATICIANS
}

\author{
CAMBRIDGE, MASSACHUSETTS, U. S. A., \\ August 30-September 6, 1950
}

An International Congress of Mathematicians will be held in Cambridge, Massachusetts, in 1950 under the auspices of the American Mathematical Society. The Society originally planned to act as host for a Congress in September, 1940, which was also scheduled to meet in Cambridge. At the 1936 Congress in Oslo, Norway, the invitation for the 1940 Congress was issued by the American delegation in the name of the American Mathematical Society. Plans for the 1940 Congress were practically completed when the outbreak of World War II in September, 1939, made it necessary for the Society to postpone the Congress to a more favorable date. An Emergency Committee was established to carry on in the interim and, on recommendation of this Committee, the Council of the Society voted to hold the Congress in 1950.

The 1950 Congress will be the third International Congress of Mathematicians to be held on the continent of North America. The first was held at Northwestern University in 1893 and the second at the University of Toronto in 1924. International Congresses were held at intervals of approximately four years, except when war intervened, until 1936. There has been no international gathering of mathematicians since that time and it is the sincere hope of the Organizing Committee that the gathering in 1950 will be a truly international one, that American mathematicians will attend in large numbers, and that all other countries will be well represented. The council of the American Mathematical Society has voted unanimously to hold a Congress which will be open to mathematicians of all national and geographical groups.

Time and Place. The dates for the Congress have been fixed as August 30-September 6, 1950. Harvard University will be the principal host institution. A number of other institutions in metropolitan Boston will join in the entertainment of Congress visitors by arranging special features on their campuses.

Type of Congress. In recent years mathematicians have been much impressed by the success of the conference method for presenting recent research in fields where vigorous advances have just been made or are in progress. In view of the success of mathematical conferences on special topics which have been held in Russia, France and Switzerland and, more recently, at the Princeton Bicentennial Celebration, 
the 1950 Congress will include Conferences in several fields. For the 1940 Congress, Conferences in four fields had been planned. The number of Conferences was thus restricted lest the introduction of a promising and novel feature result in failure through the dissipation of interest and energy. A subcommittee of the Organizing Committee, under the chairmanship of Professor A. A. Albert, is now studying the question of the number and the fields of the Conferences to be included in the 1950 Congress and the results of the committee's deliberations will be reported at a later date.

Following the established custom, the Organizing Committee plans to have a number of invited hour addresses by outstanding mathematicians. In addition, sectional meetings for the presentation of contributed papers not included in Conference programs will be held in the following fields: I, Algebra and Theory of Numbers; II, Analysis; III, Geometry and Topology; IV, Probability and Statistics, Actuarial Science, Economics; V, Mathematical Physics and Applied Mathematics; VI, Logic and Philosophy, History and Education.

The official languages of the 1950 Congress will be English, French, German, Italian, and Russian.

Organization. The plans for the Congress are under the supervision of an Organizing Committee which was elected by the Council of the American Mathematical Society in February, 1948. The Chairman is Professor Garrett Birkhoff of Harvard University and the Vice Chairman is Professor W. T. Martin of The Massachusetts Institute of Technology. Other members of the committee are: Professors J. L. Doob, G. C. Evans, J. R. Kline, Solomon Lefschetz, Saunders MacLane, Dean R. G. D. Richardson, Professors J. L. Synge, Oswald Veblen, J. L. Walsh, D. V. Widder, Norbert Wiener, and R. L. Wilder.

Many of the subventions promised for the 1940 Congress are still available. A Financial Committee under the chairmanship of Professor John von Neumann is endeavoring to secure additional funds. Besides support from Harvard University and The Massachusetts Institute of Technology, generous subventions have been subscribed for the Congress by the Carnegie Corporation, the Institute for Advanced Study, the National Research Council, and the Rockefeller Foundation.

An Editorial Committee under the chairmanship of Professor Salomon Bochner will assume responsibility for the publication of the Proceedings of the Congress.

Professor J. R. Kline of the University of Pennsylvania has been named Secretary of the Congress and Dr. R. P. Boas, Executive 
Editor of Mathematical Reviews, has been designated Associate Secretary.

Entertainment. Harvard University has offered the use of its dormitories and dining rooms for mathematicians and their guests for the period of the Congress. The Organizing Committee hopes that it will be possible to furnish room and board without charge to all mathematicians from outside continental North America who are members of the Congress. Congress membership fees and rates for room and board will be announced well in advance of the opening of the Congress.

The Entertainment Committee, of which Professor L. H. Loomis of Harvard University is Chairman, is planning many interesting features, including a reception, garden party, symphony concert, and banquet. It is hoped that American mathematicians will be able to assist in the entertainment by putting their automobiles at the disposal of the Entertainment Committee for trips to be made out of Cambridge.

Every effort will be made to facilitate the travel at reasonable cost of foreign participants while in the United States. Previous to the Congress, opportunity will be given them to see New York City under the guidance of some mathematicians.

Information. Detailed information will be sent in due course to individual members of the American Mathematical Society and to foreign mathematical societies and academies. Others interested in receiving information may file their names in the Office of the Society, and such persons will receive from time to time information regarding the program and arrangements.

Communications should be addressed to the American Mathematical Society, 531 West 116th Street, New York City 27, U. S. A. 